\title{
TRANSFERENCIA DE POLÍTICAS Y MODERNIZACIÓN ADMINISTRATIVA: HISTORIA (Y MORALEJAS) DE CUANDO EL PROGRAMA DE MEJORAMIENTO DE LA GESTIÓN CHILENO “VIAJÓ” A MÉXICO*
}

\author{
Mauricio I. Dussauge Laguna \\ London School of Economics and Political Science, Reino Unido \\ M.I.Dussauge@lse.ac.uk
}

\section{RESUMEN}

Existe en Latinoamérica una larga tradición de aprender de las instituciones y desarrollos político-administrativos de otros países. Sin embargo, el estudio de estos procesos de transferencia/difusión de políticas o aprendizaje trasnacional, como se les conoce en la literatura académica, no ha logrado consolidarse como cuestión de mayor interés entre los académicos de la región. Este artículo presenta el caso de la transferencia del Programa de Mejoramiento de la Gestión (PMG) chileno al sistema administrativo federal mexicano, cubriendo particularmente el periodo que va entre 2005 y 2008. En específico, se trata de explicar cómo y por qué el PMG acabó convirtiéndose en el Programa Especial de Mejora de la Gestión, de denominación parecida pero con objetivos y características fundamentalmente distintas. La idea central es que el PMG terminó siendo algo radicalmente diferente como resultado de una serie de conflictos y negociaciones inter(intra)-burocráticos asociados a los dos ministerios federales involucrados en el proceso: la Secretaría de Hacienda y Crédito Público (SHCP) y la Secretaría de la Función Pública (SFP). Dichos actores tenían ideas bastante distintas en cuanto a por qué tomar el PMG chileno como referencia, qué recuperar (y cómo) del esquema original y, sobre todo, cómo insertar el nuevo programa en el marco del sistema de gestión por resultados mexicano en formación.

Palabras clave: Transferencia de políticas, Gestión por resultados, Reforma administrativa, Chile, México.

* Una versión preliminar de este artículo fue presentada en las conferencias anuales de la Political Studies Association (Edimburgo) y de la International Research Society for Public Management (Berna) durante 20Io. El autor agradece a Martin Lodge, Diego Barría, Philipp Krause, Alasdair Roberts y Maira Vaca por sus muy útiles comentarios al texto original, así como a Ed Page por su invaluable asesoría en materia de transferencia de políticas. Marcela Guzmán y Javier González (y en general todas las personas entrevistadas en Santiago y Ciudad de México) fueron 


\title{
TRANSFER OF POLICIES AND MANAGEMENT MODERNIZATION: THE STORY (AND LESSONS) FROM WHEN THE CHILE'S PROGRAM FOR MANAGEMENT IMPROVEMENT 'TRAVELED’ TO MEXICO.
}

\begin{abstract}
In Latin America there is a long tradition of learning from the institutions and political-administrative development of other countries. Nevertheless, the study of these policy transfer/dissemination processes - or transnational learning, as known in academic literature- has not been able to consolidate itself as a matter of greater interest among academics in the region. This article presents the transfer of the Chilean Program for Management Improvement (PMI) to the federal administrative system in Mexico, particularly covering the period between 2005 and 2008. Specifically, it seeks to explain how and why the PMI eventually turned into the Special Program for Enhancing Federal Public Administration, with a similar name but fundamentally different objectives and characteristics. The main thrust is that the PMI ended up being something radically different as a result of a number of inter- and intra-bureaucratic conflicts associated with the two federal departments involved in the process: the Ministry of Finance and Public Credit and the Secretary of Public Affairs. Said actors held quite different opinions as to why taking the Chilean PMI as a reference, what (and how) to retrieve from the original scheme and, above all, how to insert the new program into the framework of the developing Mexican results-based management system.
\end{abstract}

Keywords: Policy transfer, Performance management, Administrative reform, Chile, Mexico.

muy generosos con su tiempo, lo cual hizo posible obtener una visión muy completa del caso analizado. Por supuesto, ninguno de ellos es responsable de los contenidos, análisis o conclusiones aquí vertidos. Una versión alternativa del texto será publicada bajo el título "Contested Policy Transfer. When Chile's Program for Management Improvement Travelled to Mexico...”, en Peter Carroll y Richard Common (eds.), Policy Transfer and Learning in Public Policy and Management, London: Routledge. Ambos textos forman parte del proyecto doctoral "Cross-National Policy Learning and 'Management by Results': Chile and México in Comparative Perspective (I99020Io)", desarrollado con el apoyo financiero del gobierno mexicano (CONACYT y Secretaría de Educación Pública) y la London School of Economics and Political Science. Las entrevistas en las que se basa el texto pudieron desarrollarse gracias al apoyo del LSE-Santander Travel Fund y la hospitalidad de las familias AcevedoValdés, Vaca-Baqueiro y Dussauge-Laguna. 


\section{INTRODUCCIÓN}

Existe en Latinoamérica una larga tradición de aprender de las instituciones y desarrollos político-administrativos de otros países. Nuestros sistemas presidenciales, arreglos federalistas, estructuras militares, esquemas de seguridad social, bancos centrales (independientes), contralorías/auditorías superiores, organismos de derechos humanos (ombudsmen), agencias/ comisiones reguladoras (independientes), listados gubernamentales de paraísos fiscales y leyes de transparencia/acceso a la información (por sólo mencionar los que vienen a la mente) tienen sus raíces, se han inspirado o han sido reformadas en algún momento de su historia con base en ideas, información o modelos extranjeros.

Sin embargo, el estudio de estos procesos de transferencia/difusión de políticas o aprendizaje trasnacional, como se les conoce en la literatura académica, no ha logrado consolidarse como cuestión de mayor interés entre los académicos de la región. Hay, por supuesto, algunos estudios que de una u otra forma se han referido a estos temas. Por ejemplo, desde hace mucho se ha analizado cómo el modelo norteamericano (presidencial y federalista) influyó en el diseño de los nuevos Estados latinoamericanos tras la independencia (e.g. Ludwikoski 2003). Más recientemente se ha discutido la transferencia de la Nueva Gestión Pública a ciertos países de la región (Nickson 2002, Bissessar 2002, Culebro 2008), lo mismo con opiniones que sostienen una influencia considerable de las ideas neogerenciales (Orellana 2004), que con algunas particularmente escépticas respecto de su poder explicativo al tratar de entender los orígenes/contenidos de los procesos modernizadores (Barzelay 2003, Cejudo 2007). Desde el mirador de la difusión de políticas (con el que los estudios de transferencia tienen mucho en común; véase Marsh y Sharman 2009), también se han producido algunas investigaciones sobre el uso de referentes internacionales en las reformas continentales en materia de política social (Weyland 2004, 2006), así como en la creación de agencias reguladoras independientes (Jordana y Levi-Faur 2005). Pero en su conjunto se trata de un número todavía muy limitado de estudios, que no siempre se insertan en una discusión teórica más amplia; aplican de manera superficial las categorías analíticas de la literatura; no discuten realmente cómo/por qué ciertas ideas de política "viajaron" hacia los países latinoamericanos; o exageran/ descartan demasiado rápido el factor transferencia y sus impactos. $\mathrm{O}$ como en el caso de los estudios sobre difusión de políticas mencionados, se trata de trabajos de expertos fuera de nuestras latitudes, que poco o ningún impacto han tenido en nuestros entornos académicos.

Frente a este escenario, en el que el aprendizaje transnacional/transferencia de políticas han ocupado un lugar central en la vida político-administrativa 
del continente, pero han sido poco atendidos por los académicos de la región, el presente artículo busca contribuir a la generación de más y mejores discusiones sobre cómo y por qué los gobiernos de la región buscan y utilizan información/lecciones/conocimiento sobre las políticas existentes en otros países, para luego (re)diseñar políticas similares en su entorno. El artículo no intenta, por supuesto, convertirse en una guía o modelo de lo que se debe estudiar, ni mucho menos de cómo debe uno aproximarse a estos temas. Por el contrario, desea simplemente mostrar que el mirador de la transferencia de políticas puede acercarnos a dimensiones de los procesos de política pública que han sido menos debatidos en nuestros ambientes académicos: ¿de dónde vienen las ideas de polítical reforma usadas por los funcionarios?; ¿cuáles son los mecanismos por los cuales dichas ideas se comunican?; o, ¿cómo se transforman las mismas al llegar a un nuevo entorno político-institucional? Éstas son cuestiones interesantes en sí mismas, pero su análisis puede además servirnos para comprender mejor, por ejemplo, las complejas relaciones existentes entre las ideas/modelos internacionales y las dinámicas nacionales de elaboración de política pública.

En términos concretos, el artículo presenta el caso de la transferencia del Programa de Mejoramiento de la Gestión (PMG) chileno al sistema administrativo federal mexicano, cubriendo particularmente el periodo que va entre 2005 y $2008^{\mathrm{I}}$. Cabe mencionar que la experiencia del PMG aquí narrada forma parte de un conjunto más amplio de reformas administrativas de gestión del desempeño/por resultados vinculadas a esfuerzos de aprendizaje transnacional que los gobiernos de Chile y México han desarrollado durante las dos décadas anteriores (Dussauge por aparecer a). Sin embargo, aquí se presenta sólo este caso tanto por razones de espacio, como porque su breve historia es suficiente para ilustrar la utilidad potencial del enfoque de transferencia de políticas en el estudio de procesos de modernización administrativa. El caso del PMG resulta útil, además, para obtener algunas moralejas sobre cuestiones de la transferencia de políticas que la literatura especializada aún no ha discutido a profundidad.

El artículo se divide en tres grandes secciones. En la primera se introducen

I Al momento de preparar la redacción final de este texto, el Programa Especial de Mejora de la Gestión (PEMG), y las referencias al mismo, parecieran haber desaparecido del sitio de internet de la Secretaría de la Función Pública (www.funcionpublica. gob.mx), que es el ministerio federal mexicano responsable de administrarlo. Dado que el periodo gubernamental en México concluye en 2012, esto podría significar que el PEMG se encuentra en una fase de evaluación o incluso terminación. Con independencia de lo que realmente esté sucediendo, la situación no afecta la historia aquí contada, ni sus posibles implicaciones teórico-analíticas. 
brevemente la literatura sobre transferencia de políticas, sus principales preguntas de investigación y los hallazgos empíricos que ha producido. En la segunda sección se describe con cierto detalle el proceso por el cual el PMG chileno "viajó" a México. Además de narrar la experiencia, la sección trata de explicar cómo y por qué el PMG acabó convirtiéndose en el Programa Especial de Mejora de la Gestión, de denominación parecida pero con objetivos y características fundamentalmente distintas. La idea central de la sección es que el PMG terminó siendo algo radicalmente diferente como resultado de una serie de conflictos y negociaciones inter(intra)burocráticos asociados a los dos ministerios federales involucrados en el proceso: la Secretaría de Hacienda y Crédito Público y la Secretaría de la Función Pública. Dichos actores tenían ideas bastante distintas en cuanto a por qué tomar el PMG chileno como referencia, qué recuperar (y cómo) del esquema original y, sobre todo, cómo insertar el nuevo programa en el marco del sistema de gestión por resultados mexicano en formación. La tercera sección del artículo trata simplemente de vincular las dos secciones anteriores con la doble intención de, por una parte, situar los elementos esenciales del caso en la discusión teórica sobre transferencia de políticas y, por la otra, resaltar cómo esta experiencia particular podría contribuir al desarrollo de nuevas líneas de investigación.

\section{EL ENFOQUE DE TRANSFERENCIA DE POLÍTICAS COMO PUNTO DE PARTIDA}

Desde principios de los I990, el enfoque de transferencia de políticas (policy transfer) se ha ido consolidando como un buen punto de partida para estudiar procesos en los que funcionarios o policymakers emplean deliberada y explícitamente información general, lecciones específicas o conocimiento sistematizado acerca de las políticas existentes en un país/ gobierno determinados para (re)definir políticas similares en su propio país/gobierno (definición propia basada en Westney 1987, Rose I99I, I993, Bennett I99I, Wolman I992, Dolowitz y Marsh I996, 2000, Evans y Davies 1999). Lo anterior implica que el enfoque de transferencia de políticas persigue varios objetivos a la vez: describir los procesos y los contenidos de las transferencias; entender las motivaciones de los actores y las formas en que aprenden de/usan experiencias internacionales; y explicar tanto los efectos de las políticas transferidas en su ambiente receptor, como la manera en que éste altera los modelos originales (Dussauge por aparecer a, por aparecer b). Se trata, pues, de un enfoque ambicioso, cuya utilidad analítica ha sido demostrada por un creciente número de estudios sobre la materia y en muy diversos campos de política sectorial (Evans 2009, Wolman 2009, Benson y Jordan 20 I I, Dussauge 20 I 2a).

En términos generales, la literatura contemporánea sobre el tema tiene 
sus antecedentes en tres fuentes de discusión académica. Primero, en los estudios sobre difusión de políticas o difusión de innovaciones, surgidos en los I960-1970 en los Estados Unidos (Walker 1969, Gray I 973, Collier y Mesick 1975, Rogers 2003). Dichos estudios se enfocaron primordialmente en describir los patrones geográficos y temporales por medio de los cuales innovaciones o políticas públicas generadas en un gobierno estatal eran adoptadas por (o "viajaban" hacia) otros estados ${ }^{2}$. Segundo, en los estudios impulsados por Richard Rose (I99I, I993, 2005) sobre el aprendizaje de lecciones (lesson-drawing), y por las contribuciones de Colin Bennett (I 991) y otros autores acerca de cómo los funcionarios/policymakers usan la información de las experiencias extranjeras para desarrollar sus políticas nacionales (Majone I99 I, Robertson I991). Y tercero, en las aportaciones de diversos estudios que, a pesar de no emplear el término transferencia de políticas, se concentraron en uno o varios de los temas que actualmente ocupan a los estudiosos de esta área. Por ejemplo, el análisis de Waltman ( I 980) sobre cómo los estadounidenses copiaron políticas impositivas y de seguridad social del Reino Unido; la narración de Westney (I987) sobre la transferencia de modelos organizacionales europeos a tierras japonesas; o la discusión de Robertson y Waltman (I 993) sobre los factores políticos que afectan la manera en que los países toman prestadas (policy borrowing) políticas de otras jurisdicciones.

Una discusión más estructurada sobre transferencia de políticas como tal no surgió, sin embargo, hasta a principios de los noventa. Aquí vale la pena destacar el texto de Harold Wolman (1992), sobre las transferencias de políticas de desarrollo urbano entre Estados Unidos y el Reino Unido; y las revisiones bibliográficas/conceptuales de David Dolowitz y David Marsh (I996, 2000; aunque véanse también Bennett 1997, Stone I999, Evans y Davies 1999). Se trata de textos en muchos sentidos distintos, con énfasis y ambiciones teóricas diferentes. Por ejemplo, Wolman se interesa más en entender cómo y hasta qué punto los policymakers realmente aprenden de las experiencias internacionales, cómo obtienen información sobre las mismas y cómo la emplean para desarrollar nuevas políticas en sus países. Por su parte, Dolowitz y Marsh introducen una visión más descriptiva y enciclopédica, en la que tratan de cubrir todos los aspectos relevantes del proceso de transferencia ${ }^{3}$ : patrones decisionales (e.g. niveles de racionalidad); factores/mecanismos explicativos (e.g. ¿aprendizaje o coerción?); resultados obtenidos (e.g. ¿éxito o fracaso?). A pesar de estas diferencias importantes, tanto Wolman como Dolowitz y Marsh se aproximan al tema de la transferencia de políticas con base en un conjunto

2 Si bien Collier y Mesick (I975) estudiaron los patrones de difusión en el ámbito internacional.

3 Aunque no sin limitaciones importantes. Véase la crítica de James y Lodge (2003). 
de preguntas de investigación relativamente similares, como se observa en la tabla I (véase también Westney I987).

\section{Tabla I: Preguntas de investigación básicas sobre procesos de transferencia de políticas}

\section{Wolman (1992)}

¿Cómo aprenden los hacedores de políticas acerca de las políticas en otros países?

¿De dónde vienen las ideas que impulsan la transferencia de políticas?

¿Cómo entran las ideas sobre transferencia de políticas al proceso político doméstico?

¿Cómo se realiza la evaluación de una política sometida a consideración de ser transferida?

¿Cómo se evalúa la relevancia y adaptabilidad potenciales de la política sometida a consideración de ser transferida?

¿Qué tipos de transferencia de política ocurren?

¿Cuáles son las características de los procesos de transferencia de políticas?
Dolowitz y Marsh (1996)

¿Qué es transferencia de políticas?

¿Quién transfiere políticas?

¿Por qué ocurre la transferencia de políticas?

¿Qué se transfiere?

¿Existen distintos grados de transferencia?

¿De dónde se aprenden lecciones?

¿Qué factores limitan la transferencia?
Dolowitz y Marsh (2000)

¿Por qué los actores [de gobierno/políticos] se involucran en la transferencia de políticas?

¿Quiénes son los principales actores involucrados en el proceso de transferencia?

¿Qué se transfiere?

¿De dónde se aprenden lecciones?

¿Cuáles son los diferentes grados de transferencia?

¿Qué restringe o facilita el proceso de transferencia de políticas?

¿Cómo se relaciona el proceso de transferencia de políticas con el éxito o fracaso de la política?

Fuente: Basado en Dussauge (20I2a).

De entonces a la fecha, buena parte de las contribuciones académicas del área han tratado de responder alguna (o varias) de las preguntas anteriores. El mismo Wolman, por ejemplo, ha seguido investigando cómo aprenden los hacedores de políticas acerca de las políticas en otros países en diversas publicaciones (Wolman y Page 2002, Mossberger y Wolman 2003). Por otra parte, en su análisis reciente sobre la transferencia del programa Gateway entre el Reino Unido y Australia (Fawcett y Marsh 20I2), 
David Marsh ha regresado al tema de “¿cómo se relaciona el proceso de transferencia de políticas con el 'éxito' o 'fracaso' de la política?”. Y otros autores han prácticamente usado todas las preguntas anteriores como guía para analizar los casos específicos de reformas administrativas surgidas en los países occidentales y luego transferidas hacia el sureste asiático y los países bálticos (Common 200I, Randma-Liiv y Kruusenberg 2012, respectivamente).

Sin afán de ofrecer una revisión bibliográfica exhaustiva, ¿cuáles han sido los principales hallazgos empíricos de la literatura ante los temas y preguntas planteadas por Rose, Bennett, Westney, Wolman, Dolowitz y Marsh? Tomando como base un conjunto de reseñas recientes (Evans 2009, Wolman 2009, Benson y Jordan 20 I I), así como algunas anteriores pero igualmente detalladas (Stone I999, Page 2000), podrían ofrecerse las siguientes respuestas. En primer lugar, los estudios sobre transferencia de políticas han dejado en claro que, ya sea como promotores del proceso o participantes directos en alguna de sus fases, los actores involucrados suelen formar parte de una o varias de las siguientes categorías: políticos y burócratas; emprendedores de políticas (que puede incluir a los anteriores, pero también otros actores; véase Mintrom 1997); académicos o comunidades transnacionales de expertos (Stone 2004); grupos de presión; organizaciones no gubernamentales (e.g. los llamados think-tanks; ver Stone 2000); organismos internacionales, como el Banco Mundial o la OCDE; e instituciones supra-nacionales, por ejemplo las que integran la base administrativa de la Unión Europea (véase Bulmer et al. 2007).

En segundo lugar, diversos estudiosos del tema han tratado de investigar las formas o procesos decisionales que caracterizan a la transferencia/ difusión de políticas. Aquí los hallazgos van desde quienes argumentan la predominancia de búsquedas racionales, es decir esfuerzos por parte de los policymakers por encontrar las mejores prácticas/o las opciones más redituables para resolver un determinado problema o situación (Meseguer 2009), hasta quienes describen experiencias en las que la transferencia de ciertas políticas fue resultado de meras coincidencias o suerte (véase Westney 1987). Y entre ambos extremos, numerosos estudios sostienen que la transferencia de políticas puede basarse en algunas variantes del modelo de racionalidad limitada, por ejemplo la búsqueda de soluciones medianamente satisfactorias, o el uso de modelos disponibles en un momento determinado que por ser tales les hacen la vida más sencilla a los tomadores de decisión (Weyland 2006). Otros estudios han sugerido la posibilidad de casos de anarquía organizacional (e.g. situaciones en los que, por una combinación no racional de factores, soluciones externas se usan para resolver problemas administrativos distintos a los que les dieron 
origen; véase Mossberger 2000). Finalmente, también se han discutido casos en los que la transferencia de programas surge de comunicaciones entre colegas que se conocen bien y confían en sus recomendaciones mutuas (Wolman y Page 2002, Page y Mark-Lawson 2010).

En tercer lugar, los especialistas han tratado de discutir las motivaciones por las cuales los países se involucran en procesos de transferencia de políticas/aprendizaje trasnacional. La propuesta inicial de Rose (I99I) fue que el aprendizaje transnacional deriva de la búsqueda de soluciones a problemas o situaciones insatisfactorias. Otras razones pueden ser la necesidad de legitimar decisiones ya tomadas o la de influir en ciertos debates de política pública (Bennett I99I, Robertson I99I). Dolowitz y Marsh $(1996,2000)$ también han argumentando que la transferencia puede originarse en procesos más bien coercitivos. Por ejemplo, en aquellos casos en los que organizaciones internacionales o instituciones supranacionales obligan a ciertos países a adoptar modelos extranjeros o prácticas internacionales (e.g. como parte de un préstamo o como condición de ingreso a una comunidad supranacional). Una variante de lo anterior, útil sobre todo para explicar experiencias históricas más que casos contemporáneos, se relaciona con escenarios de guerra/colonización, en los que países ganadores/colonialistas fuerzan a los países perdedores/ colonias a adoptar ciertas instituciones/políticas. Algunos otros estudios han sugerido que la transferencia es resultado de procesos de imitación (copia), desencadenados a su vez por diversas olas de difusión internacional (Simmons et al. 2008).

En cuarto lugar, las discusiones han subrayado la existencia de diversos grados o tipos de transferencia. En un extremo, se ha mencionado la posibilidad de que una política/institución extranjera sea transferida íntegramente a otro entorno nacional, aunque también se ha subrayado que esto sucede con poca frecuencia y no siempre con buenos resultados (véase por ejemplo Sharman 2010). En algunos casos se ha mostrado que la transferencia de casi todos los elementos del programa es también un escenario posible, sobre todo cuando los gobiernos carecen de capacidades técnico-analíticas y por lo tanto usan experiencias internacionales destacadas como modelo de referencia sin hacerles muchos ajustes (Weyland 2006, Randma-Liiv y Kruusenberg 2012). La mayoría de los estudios, sin embargo, han resaltado que generalmente sólo se transfieren algunos componentes de la política/institución de referencia, algunas ideas básicas relacionadas con la misma o algunas lecciones generales de su experiencia práctica. También se ha sugerido la posibilidad de que se aprendan/transfieran lecciones negativas (e.g. aquello que no se debe hacer; Rose I99 I, I993). Por último, en el otro extremo de este abanico de 
opciones se ha propuesto que a veces son sólo los nombres, siglas o etiquetas (policy labels) asociadas a las políticas existentes lo que se transfiere a otros contextos (Mossberger 2000, Sahlin y Wedlin 2008).

En quinto lugar, los análisis de las experiencias empíricas han también resaltado los diversos obstáculos que los procesos de transferencia de políticas suelen enfrentar. En algunos casos se han resaltado los problemas cognitivos, es decir las dificultades enfrentadas al momento de aprender de otros países (Evans 2009), incluyendo el acceso limitado a la información relevante sobre los programas de interés (Page y Mark-Lawson 2010). También se han resaltado problemas de naturaleza más bien política, como pueden ser disputas partidarias (Robertson y Waltman 1993) o las resistencias de la opinión pública (Evans 2009). Finalmente, unos cuantos estudios han sugerido que los factores institucionales pueden también condicionar tanto el desarrollo de los procesos (Page 2000, Dolowitz y Marsh 2000), como los resultados de los mismos (Lodge 2003).

Por último, y en cercana relación con el punto anterior, la literatura también ha debatido las razones por las cuales los programas/políticas transferidos se transforman al "viajar" entre naciones (Pedersen 2007). De acuerdo con la postura original de Rose (I99I, I993), por ejemplo, los cambios a los programas son consecuencia de adaptaciones deliberadas hechas por los actores involucrados en la transferencia. Para algunos otros autores, los ajustes responden a la necesidad de editar y traducir la política transferida, a fin de simplificarla y facilitar su inserción en otros entornos (Sahlin y Wedlin 2008). Y, por supuesto, buen número de estudios han sugerido que los factores culturales e institucionales ejercen una influencia poderosa en la política transferida, moldeándola y adaptándola a su ambiente político-administrativo receptor (Westney 1987, Majone I99I, Dolowitz y Marsh 1996, 2000, Stone 1999, Massey 2009).

Por supuesto, la literatura especializada ha evolucionado en muchas y muy variadas direcciones, y hoy es posible encontrar investigaciones enfocadas en temas que no aparecen necesariamente en el resumen anterior. Entre otras, podrían mencionarse investigaciones sobre la transferencia disfuncional de políticas (Sharman 2010); los vínculos entre la transferencia de políticas y la innovación gubernamental (Dussauge por aparecer d); el papel de los organismos internacionales en las distintas etapas de los procesos de transferencia (Walt et al. 2004, Dussauge por aparecer e); los procesos mediante los cuales las regulaciones internacionales son localizadas (e.g. son adaptadas al entorno local; Heilmann y SchulteKulkmann 20I I); o las distintas formas en que la variable tiempo afecta el aprendizaje transnacional (Dussauge 20 I 2C). 
Antes de concluir la sección y pasar al análisis del caso empírico, valdría la pena anotar que la literatura sobre transferencia de políticas no ha estado libre de críticas más o menos justificadas. Por ejemplo, algunos autores han sugerido que el mismo término transferencia de políticas es inadecuado, en tanto que sugiere la idea de un proceso relativamente sencillo, en el que un programa se traslada de un lugar a otro de forma casi automática, sin mayores cambios o complicaciones (Massey 2009, Page y Mark-Lawson 20I0). Otros autores han sostenido que la literatura ofrece más un listado de preguntas que un conjunto de propuestas teóricas sólidas (James y Lodge 2003, Evans y Davies 1999). También se ha criticado la limitada atención que los estudios de estos temas han prestado a la variable tiempo (Stone I999, Page 2000), o la idea de que los procesos involucran simplemente a un país exportador y a un país importador (Pollitt 2003). Aunque la tercera sección tratará de volver a algunos de estos temas, una discusión más detallada queda fuera de los alcances de este texto. Valga simplemente dejar mencionados los temas para ahora sí pasar al análisis de cuando el PMG chileno "viajó" a México, con base en las preguntas y temas de la literatura aquí reseñada.

\section{DE SANTIAGO DE CHILE A LA CIUDAD DE MÉXICO: LA TRANSFERENCIA (Y TRANSFORMACIÓN) DEL PROGRAMA DE MEJORAMIENTO DE LA GESTIÓN}

Para ofrecer una visión sencilla, pero a la vez completa, del proceso de transferencia del Programa de Mejoramiento de la Gestión chileno a México, así como de su posterior transformación en el PEMG, esta sección se divide en cuatro apartados. Primero se ofrecen algunas características generales del modelo original chileno. Segundo, se narra el proceso general por el cual el PMG "viajó" entre ambos países. Tercero, se trata de explicar cómo y por qué el PMG cambió de nombre y contenidos al introducirse en el sistema administrativo mexicano. Finalmente, se comparan las características básicas de ambos programas para ofrecer una visión panorámica de sus similitudes y diferencias más importantes. La historia aquí contada se reconstruye a partir de los comentarios ofrecidos por casi una veintena de funcionarios públicos ( $\mathrm{y}$ algunos expertos académicos) chilenos y mexicanos durante un conjunto de entrevistas semi-estructuradas realizadas entre 2009 y 20 I I, así como con datos de documentos oficiales de ambos gobiernos ${ }^{4}$.

4 Los detalles de dichas entrevistas pueden encontrarse en otro texto (Dussauge por aparecer c), mismo que ha servido de base para preparar la narración del caso. 


\section{El modelo chileno: los Programas de Mejoramiento de Gestión}

La historia de los Programas de Mejoramiento de Gestión, o PMG, ha sido contada ya muchas veces (Armijo 2003, Ramírez 2004, Guzmán 2005, 20 I I, Arenas y Berner 20 I0, Dussauge 20 I2b). Sin embargo, quizás valga la pena hacer un breve recuento de sus orígenes, evolución y características generales para luego entender qué programa estudiaron los funcionarios mexicanos y explicar hasta qué punto retomaron o no (y por qué) sus atributos esenciales.

Los PMG se crearon formalmente en 1998 por medio de la ley No. I 9.553 y desde sus orígenes fueron herramientas enfocadas en alcanzar múltiples objetivos a la vez. Por un lado, como su nombre lo indica, se trató que los PMG fueran instrumentos útiles para mejorar el desempeño de las instituciones del gobierno central chileno y, concretamente, de sus capacidades de gestión interna. Pero por el otro lado, los PMG surgieron antes que todo como una respuesta para vincular los incrementos salariales de los servidores públicos con la consecución (o no) de los objetivos institucionales (Guzmán 20II). Más adelante, cuando la Dirección de Presupuestos (DIPRES) creó el Sistema de Control y Evaluación de la Gestión Pública en 2000, los PMG empezaron a contribuir además (o por lo menos de forma más clara y directa) al proceso de toma de decisiones presupuestales del gobierno (Zaltsman 2009).

En cuanto a su desarrollo, podría decirse que los PMG han pasado por cuatro etapas (véase, para lo que sigue, Arenas y Berner 20 Io). En la primera, que va de 1998 a 2000 , fueron las propias instituciones las encargadas de preparar sus indicadores, metas y objetivos a alcanzar de acuerdo con sus propias prioridades. Sin embargo, según diversas valoraciones realizadas por DIPRES, este enfoque no fue del todo adecuado por varias razones: las instituciones presentaban información difícil de analizar; prácticamente todos los funcionarios obtenían los incentivos monetarios; y no había realmente forma de saber si los PMG habían mejorado o no el funcionamiento de los servicios o ministerios participantes (Marcel 2000, Guzmán 2005, 20 I I, Arenas y Berner 2010). Una segunda etapa de los PMG podría establecerse entre 2000 y 2005 , caracterizada por el deseo de transformar dichos instrumentos en mecanismos de benchmarking, que realmente permitieran hacer comparaciones entre instituciones y a la largo del tiempo (Marcel 2006). Para ello, los PMG se estructuraron sobre la base del llamado Programa Marco, que aplicaría a todas las instituciones participantes, integrado por cinco áreas y once sistemas (véanse Guzmán 2005, Arenas y Berner 20 I I). Una tercera etapa del programa comenzaría en 2005, cuando se añadió el Programa Marco Avanzado, mientras que el anterior se convirtió en Programa Marco Básico. El cambio trajo consigo 
esquemas de verificación y certificación basados en las normas ISO 900I, con el objetivo de agregar un actor certificador externo distinto a DIPRES. Finalmente, a las etapas señaladas por Arenas y Berner (2010) podría agregarse una cuarta a partir de 20 io. En este caso, la llegada de una nueva coalición gobernante pareciera haber traído consigo tanto una simplificación del diseńo/funcionamiento de los PMG, como una disminución en la importancia atribuida a la herramienta.

El desarrollo e implementación cotidiana de los PMG han sido coordinados por DIPRES (Guzmán 2005, 201 I, Arenas y Berner 2010; Dussauge 20I2), si bien muchos otros actores han participado en el proceso. Los ministerios y servicios públicos, por ejemplo, son responsables de definir (con el apoyo de DIPRES) sus metas de desempeño y objetivos anuales. El Comité Triministerial, integrado por el Ministerio del Interior, el Ministerio Secretaría General de la Presidencia y el Ministerio de Hacienda tiene la responsabilidad de garantizar la coherencia, objetividad y niveles de exigencia de los objetivos acordados (Guzmán 2005). Una Red de Expertos formada por servidores públicos especialistas en los diversos temas específicos de gestión, contribuyen a revisar y mejorar los contenidos de los mismos. Finalmente, con la introducción de los esquemas ISO 900 I, se agregó la participación de agencias certificadoras externas. Sin embargo, es ampliamente reconocido que DIPRES se ha mantenido como el centro neurálgico del sistema, tanto por su liderazgo conceptual en la materia, como por su poder (formal e informal) sobre la distribución de recursos presupuestales. Además, DIPRES ha hecho uso intensivo de la información aportada por los PMGs para definir incrementos salariales anuales y ajustes en las aportaciones presupuestarias institucionales (Zaltsman 2009).

En resumen, cuando los funcionarios mexicanos conocieron a detalle el PMG chileno, se encontraron con una herramienta de gestión bastante institucionalizada; coordinada en términos globales por la DIPRES; integrada en un sistema de evaluación y control más amplio; y vinculada con las políticas de remuneración y presupuestación del gobierno central chileno. ¿Qué se transfirió a México? ¿Quiénes participaron en el proceso y por qué? ¿Con qué resultados? Los siguientes tres apartados tratan de responder dichas preguntas.

\section{Los orígenes del PMG MEXICANo}

En términos formales, resulta relativamente sencillo saber cuándo se creó el PMG mexicano. Por una parte, el 4 de diciembre de 2006, el presidente Felipe Calderón emitió un "Decreto que establece las medidas de austeridad y disciplina del gasto de la Administración Pública Federal" (Diario Oficial 2006). En el artículo 6 de dicho documento se estableció 
que "[l] as medidas previstas en el presente Decreto se orientarán a generar ahorros en el mediano plazo y se vincularán al Programa de Mejoramiento de la Gestión, con el objeto de promover la modernización de la gestión pública”. Por otra parte, casi dos ańos después, el 9 de septiembre de 2008, el mismo presidente Calderón emitiría el decreto que aprobó la creación del Programa Especial de Mejora de la Gestión en la Administración Pública 2008-20I2 (Diario Oficial 2008). Así, mientras que el primer decreto, preparado por la Secretaría de Hacienda y Crédito Público (SHCP, en adelante), introdujo el PMG al derecho administrativo mexicano, el segundo fue redactado por la Secretaría de la Función Pública (SFP, en adelante) y marcó el inicio formal de su implementación.

Ahora bien, como en el caso de casi cualquier proceso de transferencia de políticas, resulta un poco más complicado encontrar los orígenes informales, los mecanismos y las razones por los cuales los funcionarios de un país determinado (México), se interesaron en las políticas o programas existentes en otro (Chile) y decidieron aprender de su experiencia. Aunque es difícil determinar en qué momento exacto los funcionarios mexicanos se interesaron en estudiar con mayor detenimiento el Sistema de Evaluación y Control de Gestión de la DIPRES, y en particular los PMG, es posible afirmar que se enteraron de estas experiencias durante la primera mitad de los 2000. Por ejemplo, Carlos Hurtado, Subsecretario de Egresos de la SHCP durante 2000-2006, conoció a Mario Marcel (Director de la DIPRES en el mismo periodo y principal impulsor de las reformas de gestión por resultados en Chile desde los noventa) durante las reuniones de los Senior Budget Officials (SBOs) en la OCDE. Si bien en esos años Chile no era miembro de la organización, Marcel participaba como observador en las reuniones de los SBOs y en varias ocasiones tuvo la oportunidad de presentar el SECG chileno. Ambos funcionarios coincidieron además en otras reuniones internacionales sobre temas de reforma presupuestaria (incluyendo sus componentes de orientación a resultados) realizadas en Santiago bajo el auspicio de la CEPAL y con el patrocinio del Ministerio de Hacienda de Chile, la Organización para la Cooperación y el Desarrollo Económicos, el Banco Interamericano de Desarrollo, el Banco Mundial y el Fondo Monetario Internacional (Dussauge por aparecer a).

Más o menos por esos mismos años, otro grupo de funcionarios mexicanos de la Secretaría de Desarrollo Social (SEDESOL, en adelante) se encontraban también recopilando información sobre herramientas internacionales de evaluación y monitoreo, entre las cuales se encontraron con el caso del sistema chileno. Los funcionarios de la Dirección General de Monitoreo y Evaluación de los Programas Sociales estaban buscando experiencias relevantes para mejorar sus esquemas de trabajo y, sobre 
todo, para preparar la entonces próxima creación del Consejo Nacional de Evaluación de la Política Social (CONEVAL, establecido en 2004 como una institución semi-autónoma encargada de coordinar el desarrollo de evaluaciones de los programas sociales financiados por el gobierno federal).

Durante un seminario internacional, celebrado en junio de 2005 en Washington, DC, patrocinado por el BM y el BID, se presentaron las experiencias de monitoreo y evaluación de diversos países latinoamericanos, incluidos los casos de Chile y México. En esa ocasión participaron como presentador Gonzalo Hernández (quien entonces era Director General de Monitoreo y Evaluación en SEDESOL y futuro Secretario Ejecutivo de CONEVAL) y Guillermo Bernal (Jefe de la Unidad de Control Presupuestario de la SHCP) como comentarista. Aunque Hernández ya conocía algo de la experiencia chilena, expresó su interés en saber más del tema, incluyendo cómo vincular las evaluaciones de programas con las decisiones presupuestales (May et al. 2006). Para Bernal, en cambio, el seminario quizás representó la oportunidad de conocer por primera vez de cerca tanto la experiencia de SEDESOL como la del gobierno chileno, si bien es probable que conociera algo acerca de este último dados los contactos previos entre Hurtado y Marcel.

En los meses siguientes, Bernal y su equipo intercambiaron información sobre el sistema chileno con sus colegas de SEDESOL-CONEVAL y entraron en contacto con funcionarios chilenos en DIPRES. Con el apoyo de donaciones del BID (otorgadas para el desarrollo de un sistema de presupuesto basado en resultados), durante la primera mitad de 2006 viajó a Santiago una delegación de funcionarios integrada por Bernal, Max Diener (Director General Jurídico de SHCP, quien había participado en las reformas presupuestales de los I990s) y un equipo de asesores. Los integrantes de la delegación se reunieron con sus contrapartes en DIPRES, y con Mario Marcel (ex-Director de Presupuestos) y Marcela Guzmán (exJefa de la División de Control de Gestión). Tanto Marcel como Guzmán habían dejado recientemente sus puestos en DIPRES y trabajaban como consultores. Poco tiempo después comenzarían a asesorar al gobierno mexicano por encargo del BID.

En el transcurso de estas reuniones, los funcionarios mexicanos obtuvieron información detallada sobre el sistema presupuestal chileno, el SECG y los PMG, la cual les serviría posteriormente para construir el sistema mexicano de presupuesto basado en resultados (Dussauge, por aparecer a). Mientras que en años previos los funcionarios de la SHCP habían estudiado los sistemas y reformas presupuestales de países desarrollados (e.g. Estados Unidos, Reino Unido, Holanda), siempre habían tenido presente que las diferencias culturales e institucionales entre 
dichas naciones y México eran muy importantes. En el caso de Chile, sin embargo, los funcionarios mexicanos encontraron un modelo que en principio parecía más fácil de copiar, tanto por los aspectos comunes a ambos países (e.g. sistemas presidenciales, misma cultura/lenguaje), como por el buen diseño institucional del esquema chileno.

Con respecto al PMG en particular, la serie de entrevistas con gente de DIPRES y las reuniones con Marcel y Guzmán habían dejado entre los funcionarios de la SHCP la idea de que se trataba de una "herramienta maravillosa" (entrevista citada en Dussauge, por aparecer c). Ahora bien, además de la valoración de los PMG en sí mismos, los funcionarios mexicanos se interesaron en dicho instrumento porque estaba claramente inserto en el SECG, es decir en un esquema más amplio de gestión/ presupuesto por resultados. Y esto es lo que los funcionarios mexicanos estaban buscando. De hecho, de acuerdo con uno de ellos, "el PMG representaba la posibilidad de convertirse en una herramienta para ahorrar". Además, les permitía "estructurar el decreto de austeridad" que más tarde prepararían para el presidente Calderón, y en el cual insertarían el concepto del PMG, como se mencionó anteriormente.

Así, entre mediados de 2005 y finales de 2006, los funcionarios de laSHCP habían conocido el SECG chileno y sus vínculos con la presupuestación orientada a resultados. Visitaron Santiago para obtener información más detallada de cómo funcionaban el sistema y sus componentes específicos, y se llevaron algunas lecciones sobre qué y cómo podían transferir algo parecido a México. De hecho, durante los ańos siguientes los contactos entre funcionarios de SHCP y DIPRES traerían consigo un conjunto de influencias importantes en la forma en que el presupuesto basado en resultados mexicano finalmente se echaría a andar (Dussauge por aparecer a).

\section{Del PMG al PEMG}

$\mathrm{Al}$ momento de integrar el término PMG en el decreto de austeridad de diciembre de 2006, los funcionarios de SHCP formalmente transfirieron la herramienta al sistema mexicano. Pero al mismo tiempo, pusieron en marcha un conjunto de eventos que alteraría de manera sustancial los contenidos de dicho programa. Y es que al poco tiempo de publicado el decreto, funcionarios de la Secretaría de la Función Pública (SFP) notaron que el decreto incluía iniciativas que invadían el marco de atribuciones legales de su institución. De hecho, desde mediados de los I990s, la SFP había puesto en marcha diversas acciones orientadas a fortalecer la evaluación y la gestión del desempeño, como parte de su doble misión institucional de controlar la corrupción gubernamental y modernizar la 
estructura administrativa (Pardo 2009). A pesar de ello y de que el PMG estaba siendo usado de forma explícita como herramienta para modernizar la gestión pública por la SHCP, la SFP no había sido consultada cuando se redactaron los contenidos del decreto de austeridad. Tampoco habían sido informados que la SHCP estaba planeando introducir una versión mexicana del PMG chileno como parte del proceso de reforma presupuestal que se estaba diseñando.

Tras la publicación del decreto, los funcionarios de la SFP contactaron a sus colegas en la SHCP para coordinar las acciones siguientes. La primera consecuencia fue que los funcionarios de la SFP fueron finalmente involucrados en la redacción de las regulaciones suplementarias al decreto de austeridad, que aparecieron el 29 de diciembre de 2006. Pero además, arguyendo que las cuestiones relacionadas con el PMG (e.g. modernización, gestión pública) en realidad eran parte de su mandato legal, la SFP reclamó la responsabilidad respecto a cómo debería concretarse la versión mexicana del programa. Si bien los funcionarios de la SHCP no estaban del todo convencidos de dejar ir el control sobre el proceso de transferencia de dicha herramienta, el PMG pasó a la SFP.

Poco después, en marzo de 2007, un grupo de funcionarios de la SFP, liderado por el Subsecretario (y algunos meses después secretario) de la Función Pública, Salvador Vega, viajó a Santiago para estudiar nuevamente la estructura y funcionamiento del PMG. Como lo habían hecho sus colegas de la SHCP algunos meses antes, los funcionarios de SFP se reunieron con expertos de la DIPRES. Sin embargo, para obtener una visión más comprehensiva del PMG, también se reunieron con algunos expertos académicos y con representantes de otros servicios y ministerios chilenos. Meses más tarde harían una visita más a Santiago, aunque en esa ocasión junto con funcionarios de la SHCP, así como con algunos consultores del BID. Aparte de sus reuniones con la gente de DIPRES, los funcionarios se reunieron en varias ocasiones con Guzmán, quien era la consultora líder contratada por el BID para asesorarles (Marcel había asumido un puesto directivo precisamente en el BID.) En el transcurso de esta nueva ronda de reuniones, los servidores públicos de la SHCP se enfocaron en temas presupuestarios y de evaluación, y los de la SFP en las cuestiones relacionadas con el PMG.

De acuerdo con algunos participantes, durante la primera mitad de 2007 los funcionarios de ambas secretarías mexicanas se reunieron repetida y productivamente para discutir las diversas herramientas que habrían de incluir el nuevo esquema mexicano de gestión por resultados. Entre otras cosas, se discutieron el futuro Sistema de Evaluación del Desempeño, el PMG y la manera en que éste y las evaluaciones desarrolladas por 
CONEVAL en el ámbito de las políticas sociales habrían de integrarse. Ambas instituciones acordaron, además, que todas las dependencias/ entidades federales recibirían fondos especiales para garantizar una adecuada implementación del PMG.

Las cosas, sin embargo, cambiaron radicalmente hacia julio del mismo año. Las relaciones entre ambas instituciones se deterioraron debido a fuertes desacuerdos respecto de los contenidos y fines que el PMG debía perseguir, así como por conflictos acerca de qué secretaría debía mantener el liderazgo del programa y su implementación. Desde la perspectiva de la SHCP, la culpa era de los funcionarios de la SFP, quienes no habían sabido cómo copiar el PMG a pesar de todas las facilidades que se les habían otorgado (e.g. información inicial, contactos, fondos internacionales del BID). Pero desde la perspectiva de la SFP, el problema se originaba en que la SHCP nunca había estado de acuerdo con ceder el control del proyecto. Más aún, la forma en que el PMG mexicano había ido evolucionando en las propuestas preparadas por la SFP poco tenía que ver con las ideas originales de los funcionarios de SHCP. Mientras que estos habían visualizado un PMG enfocado a la austeridad y eficiencia en el gasto, la línea seguida por la SFP trataba de resaltar la modernización y mejora administrativas.

A estas complejidades y conflictos inter-organizacionales habrían de sumarse una serie de tensiones dentro de la propia SFP. De acuerdo con un integrante del equipo redactor, entre el comienzo del proceso (enero 2007) y la publicación de la versión definitiva (septiembre 2008) se discutieron alrededor de nueve versiones distintas del PMG. Además, unas cuantas semanas antes de la presentación oficial del PMG, tanto el texto a publicar como el decreto presidencial fueron modificados para introducir el término Programa Especial de Mejora de la Gestión. El Secretario Vega consideró que, si bien mejoramiento y mejora significaban lo mismo, ésta última sonaba más natural en el español hablado en México que el término original.

Las complicaciones se acentuaron, asimismo, por otros factores. Primero, la necesidad de conciliar los contenidos del nuevo programa con diversas iniciativas de modernización puestas en marcha en el gobierno previo y que todavía estaban vigentes. Segundo, la inclusión de expertos del Banco Mundial en el proceso de diseño del programa, quienes no sólo contaban con una visión distinta a la de los asesores del BID y de la SHCP, sino que además tenían intereses propios. Tercero, la puesta en marcha de un proceso de restructuración interna en la SFP que, aparte de introducir distracciones adicionales, afectó la composición de la estructura del equipo encargado de preparar la transferencia del PMG. 
Ahora bien, quizás el problema más importante es que los funcionarios de la SFP en realidad nunca compartieron la visión de sus colegas en SHCP sobre el sistema chileno, ni en particular sobre las virtudes potenciales del PMG. A pesar del proceso de estudio-aprendizaje que se había puesto en marcha en meses previos (viajes a Santiago, asesoría de expertos chilenos, análisis de documentación relevante), los funcionarios de la SFP nunca pensaron que las herramientas chilenas de gestión por resultados fueran tan desarrolladas o útiles como se había sugerido. Por una parte, desde mediados de los 1990 funcionarios de la SHCP habían estado buscando ideas y herramientas que pudieran servirles para reformar el esquema presupuestario mexicano y convertirlo en algo más vinculado a resultados institucionales. Por lo tanto, es muy probable que se hayan fijado en las similitudes entre los casos chileno y mexicano, pensando que el SECG y el PMG en particular podrían servirles como ejemplo a seguir. Por otra parte, los funcionarios de la SFP tenían otras prioridades en materia de modernización administrativa. Además, al integrarse al proceso de transferencia del PMG, inmediatamente se enfocaron en entender las diferencias entre los dos sistemas administrativos, para ponderar la aplicación de la herramienta chilena en el nuevo entorno mexicano. Sus preocupaciones eran distintas y en parte más pragmáticas, pues debían preparar un programa factible en la práctica, que integrara las prioridades del secretario y las herencias de estrategias modernizadoras previas, y que además impulsara una nueva agenda de cambios administrativos. Y todo ello sobre la base de un modelo extranjero que no había sido de su elección.

\section{El PEMG mexicano vis-à-VIS el PMG ChILeno}

Al final del día, el PEMG mexicano ciertamente recuperó algunos elementos del PMG chileno, pero los detalles específicos del nuevo programa en realidad poco tuvieron que ver con el modelo original. Puesto en otros términos, el ambicioso y en apariencia fácil proceso de transferencia de políticas que había sido iniciado en 2005-2006 arrojó como resultados un proceso de reforma complejo y conflictivo, así como un programa radicalmente distinto, publicado con dos años de desfase con respecto a su introducción formal.

El documento de la SFP que presentó oficialmente el PEMG en 2008 es un buen punto de partida para entender las similitudes y, sobre todo, las diferencias principales entre ambos programas. En dicho documento se dice que el programa tiene como propósito "convertirse en la palanca que ayude a toda actividad pública a lograr sus mayores y mejores efectos" (Secretaría de la Función Pública 2008: 9). Asimismo, se indica que el programa "medirá y evaluará los avances en el desarrollo interno de las instituciones de la Administración Pública federal, así como la efectividad 
de sus programas y servicios". Todo lo anterior pareciera apuntar hacia objetivos y herramientas (evaluación, metas, mejoras internas) similares a los existentes en el PMG chileno. Pero más allá de estos paralelos, ambos programas muestran una lógica central distinta desde el principio. Mientras que el PMG chileno funciona como componente de un sistema de gestión/ presupuestación por resultados más amplio (el SECG), la SFP decidió usar al PEMG como la plataforma central de su estrategia de modernización administrativa para el periodo 2008-20 I2 (De hecho, el PEMG desplazó de las prioridades de la institución al Programa Nacional de Rendición de Cuentas, Transparencia y Combate a la Corrupción, 2008-2012).

Otras diferencias importantes también pueden observarse en los objetivos generales de ambos programas. El PEMG, por ejemplo, se enfocó en "maximizar la calidad de los bienes y servicios que presta la Administración Pública Federal"; "incrementar la efectividad de las instituciones"; "minimizar los costos de operación y administración de las dependencias y entidades" (Secretaría de la Función Pública 2008: 27-28). Para alcanzar dichos objetivos, la SFP propuso una serie de estrategias, líneas de acción, indicadores y metas relacionados con temas como desregulación interna, estandarización de servicios, uso de las opiniones ciudadanas, tecnologías de información, gestión del desempeño y mejora de la gestión de recursos humanos, entre otros. Ahora bien, todos estos temas ya habían estado presentes en las estrategias de modernización de gobiernos previos (Dussauge 2008, Pardo 2009). Por otra parte, si bien las estrategias comprendían preocupaciones acerca de la gestión interna, las capacidades administrativas y el desempeño de las instituciones, temas centrales en el PMG chileno, en realidad el énfasis del programa mexicano se encontraba en aspectos de calidad en el servicio, control de costos administrativos y desregulación.

En cuanto a su diseño interno, al parecer la SFP sí empleo en parte lecciones obtenidas del programa chileno al momento de estructurar el PEMG. Por ejemplo, el enfoque de sistemas del PMG ofreció a los funcionarios de la SFP un medio para aumentar la coherencia interna del nuevo programa, sobre todo frente a la falta de coordinación y priorización que habían caracterizado a la Agenda de Buen Gobierno de 2000-2006 (Dussauge 2008). La idea de tener un marco común para todas las instituciones del gobierno federal, como se usaba en el caso chileno, pareció igualmente relevante. En consecuencia, el PEMG incorporó un componente estándar, enfocado en mejorar las áreas de gestión que fueran comunes a las diversas instituciones federales (Secretaría de la Función Pública 2008: 39). Por otra parte, los funcionarios de la SFP también pensaron que el PMG chileno impulsaba la estandarización más allá de 
lo necesario, y por lo tanto agregaron un componente específico que sería aplicado de manera flexible en cada una de las instituciones (González 2008, Secretaría de la Función Pública 2008: 40).

Otros aspectos específicos del PEMG también develan diferencias respecto del modelo chileno. En el caso del PMG original, el vínculo entre la consecución de objetivos institucionales y la entrega de incentivos monetarios ha sido un componente esencial del funcionamiento de dicho programa desde su creación (Guzmán 20 I I). Sin embargo, en el programa mexicano estos vínculos no llegaron a definirse bien, a pesar de que se contemplaba la posibilidad de "carácter económico para compensar y estimular el buen desempeño de las instituciones y, en su caso, de los servidores públicos" (Secretaría de la Función Pública 2008: 49). Asimismo, los vínculos entre el PEMG y la preparación de la política presupuestal tampoco llegaron a concretarse con claridad (por lo menos en el periodo estudiado). Como se ha mencionado antes, el decreto presidencial sí había contemplado que este vínculo entre PEMG-presupuesto existiera. Pero las regulaciones complementarias no llegaron a explicar en detalle cómo hacer la relación entre el cumplimiento de metas asociadas al PEMG en cada una de las instituciones federales y la asignación de sus presupuestos. A diferencia del caso chileno, en donde tanto la operación del PMG como la hechura de la política presupuestaria recaen en la DIPRES, en México distintas instituciones son responsables de cada una de las actividades. Por lo tanto, su vinculación en el marco de una política de presupuestos basados en resultados no ha sido tan sencilla.

Una última diferencia que vale la pena señalar se relaciona con el uso de las normas ISO 900I. Como se indicó antes, cuando los funcionarios mexicanos conocieron el sistema chileno, éste se encontraba en un proceso de cambio para integrar estándares y certificaciones basadas en la norma ISO 900 I. Sin embargo, los funcionarios de la SFP no consideraron que eso fuera una verdadera innovación, ni mucho menos algo deseable de replicar en la versión mexicana del programa. De hecho, la SFP había pasado por una compleja y poco positiva experiencia con el uso de normas similares, impulsadas como parte de la Agenda de Buen Gobierno (Dussauge 2008, Pardo 2009). En consecuencia, el uso de ISO 900 I estuvo, desde el principio, fuera de las discusiones en la estructuración del futuro PEMG. 


\section{Tabla 2: Comparación del PMG chileno y del PEMG mexicano}

\author{
Aspecto \\ Lógica general del programa \\ Institución que coordina el \\ programa y su implementación \\ general \\ ¿Basado en indicadores/metas \\ de desempeño? \\ ¿Aplicación generalizada en \\ las instituciones del gobierno \\ central/federal?
}

Enfoque del programa

Sistemas específicos empleados

\section{¿Vínculos con decisiones} presupuestarias?

¿Vínculos con incentivos monetarios para los servidores públicos?

¿Vínculos con normas ISO 9001?
PMG chileno

PMG es un componente del Sistema de Control y Evaluación de la Gestión Pública

Dirección de Presupuestos

Sí

Sí

Gestión interna

Desempeño

Motivación de los servidores públicos

Capacitación

Higiene-seguridad y mejoramiento

de ambientes de trabajo

Evaluación del desempeño

Oficinas de información, reclamos y sugerencias

Gobierno electrónico

Planeación / Control de gestión

Auditoría interna

Gestión territorial

Sistemas de compras y contrataciones del sector público

Administración financiero-contable Enfoque de género

\section{PEMG mexicano}

PEMG representa la política de modernización administrativa

Secretaría de la Función Pública

Sí

Sí

Gestión interna

Desempeño

Reducción de costos

Desregulación

Participaciones de los ciudadanos

Procedimientos administrativos y servicios de calidad

Gobierno digital

Participación ciudadana

Mejora regulatoria interna

Racionalización de estructuras
Originalmente propuestos, pero procedimientos no definidos con claridad (inexistentes en la práctica)

Considerados posibles, pero procedimientos no definidos con claridad (inexistentes en la práctica)

No

Fuente: Elaboración propia con base en Guzmán (2005), Arenas y Berner (20I0), y Secretaría de la Función Pública (2008, 20I0). 
Como se describe en la tabla 2, el PEMG mexicano terminó siendo una herramienta fundamentalmente distinta del PMG chileno que le sirvió de inspiración original. Además, con el paso de los años, las diferencias acabarían siendo aún más grandes, a medida que la SFP fue adaptando el programa como resultado de su proceso de implementación. Por ejemplo, las regulaciones publicadas en 20 Io señalaban que la operación del programa cambiaría hacia el uso de proyectos de mejora (Secretaría de la Función Pública 20 Io: 2-3), que poco tienen que ver con la lógica chilena de construir un conjunto de capacidades administrativas mínimas homogéneas. En conclusión, si bien ambos programas compartieron algunas características comunes, las diferencias entre ellos parecen haber sido aún mayores, tanto en términos de sus objetivos y estructuración interna, como en su administración cotidiana y sus vínculos con las políticas de remuneraciones/gestión presupuestaria. $\mathrm{O}$ como lo dijo un funcionario entrevistado, el PEMG resultó ser "20\% chileno y 80\% mexicano".

\section{LAS MORALEJAS DE LA HISTORIA: EL PMG-PEMG Y LOS ESTUDIOS DE TRANSFERENCIA DE POLÍTICAS}

La sección anterior ha tratado de describir en detalle el proceso por el cual el PMG chileno se transfirió a México durante los años de 2006-2008. Como se ha mostrado, la transferencia de dicho programa en realidad desembocó en un proceso más complejo de lo planeado, y tuvo como resultado un producto distinto al que originalmente se pensó. Ahora bien, si tomamos distancia de la experiencia particular y la miramos como un estudio de caso desde la literatura sobre transferencia de políticas, ¿qué podemos sacar en limpio? Por una parte, con base en los temas y preguntas básicos de la literatura, podríamos tratar de resumir las similitudes de esta experiencia con los hallazgos empíricos sintetizados en la segunda sección de este texto. Por la otra, podríamos tratar de extraer algunas conclusiones/ implicaciones más generales sobre cómo la transferencia de este programa de modernización administrativa en específico puede enriquecer las discusiones teóricas sobre el tema. Las páginas finales de este artículo habrán de dedicarse precisamente a discutir estas dos cuestiones.

\section{La Transferencia del PMG-PEMG a La LUZ de los ESTUdios PREVIOS}

Si retomamos lo discutido en la segunda sección de este artículo para reinterpretar el proceso de transferencia del PMG-PEMG, es posible notar que buena parte de los hallazgos empíricos de investigaciones anteriores se encuentran presentes también en este caso. En primer lugar, en cuanto a los actores involucrados en el proceso, se puede observar la participación de funcionarios públicos de por lo menos tres instituciones del gobierno federal mexicano (SFP, SHCP y SEDESOL-CONEVAL), 
así como funcionarios de la DIPRES en el gobierno central chileno. Aunque de manera más tangencial, también participaron funcionarios de otras instituciones chilenas, quienes fueron entrevistados durante las misiones de aprendizaje en 2007 por personal de la SFP. En el proceso participaron, asimismo, representantes de los organismos internacionales (BID y Banco Mundial) y algunos consultores (Marcel, Guzmán) contratados por aquéllos, aunque su importancia en términos de definir los contenidos del programa finalmente transferido no pareciera haber sido crucial al contrastarse con el protagonismo ejercido por los policymakers mexicanos. En términos de actores políticos, pareciera que sólo tuvo un cierto involucramiento en el proceso el subsecretario (y luego secretario) de la Función Pública, Salvador Vega. Algunos académicos también fueron consultados sobre el tema durante los viajes de las delegaciones mexicanas, pero sería difícil decir que tuvieron un papel central en el proceso. No resulta claro tampoco que think-tanks, redes de expertos internacionales o emprendedores de políticas hayan tenido una participación directa en esta experiencia. Sin embargo, en el caso de estos dos últimos actores (así como del papel desempeñado por los organismos internacionales), cabe mencionar que la historia quizás habría sido un poco distinta de haberse presentado en su conjunto el proceso de transferencia de instrumentos de gestión por resultados que ha tenido lugar en ambos países durante el período i 990-20 Io (véase Dussauge por aparecer a).

En segundo lugar, la forma en que se desarrolló el proceso de transferencia del PMG en sus orígenes pareciera combinar (no sin dejos de contradicción) una búsqueda relativamente racional de soluciones adecuadas con algunos elementos de coincidencia. Por una parte, los funcionarios de la SHCP llevaban ya varios años tratando de hallar ideas/modelos útiles para construir un sistema de gestión presupuestaria que permitiera vincular las decisiones de asignación de gasto con los resultados obtenidos por los programas gubernamentales. De hecho, la participación en foros internacionales como la OCDE les había permitido conocer de cerca los esquemas internacionales más desarrollados. Por la otra, que los funcionarios mexicanos hayan coincidido en los mismos foros internacionales de CEPAL y luego BID-Banco Mundial junto con sus contrapartes chilenos, y que esto les haya permitido acercarse al modelo chileno que desconocían, pareciera subrayar también factores más casuísticos, si bien insertos en la dinámica antes mencionada de búsqueda de soluciones adecuadas para la reforma presupuestal mexicana. Al mismo tiempo, durante lo que podría denominarse como una segunda fase de la transferencia, es decir cuando la SFP asume las riendas del proceso, pareciera que las actividades siguieron un proceso de anarquía organizada más que otra cosa. Por un lado se presentó una solución (e.g. el PMG 
chileno) hasta cierto punto inesperada por los funcionarios de la SFP. Por el otro lado, estos mismos funcionarios se encontraban en los comienzos de un sexenio y, por lo tanto, enfrentaban la necesidad de desarrollar una estrategia o plan de modernización administrativa. Así, la inclusión del PMG por parte de la SHCP en el decreto de austeridad les representó un asunto problemático, un reto a su área de responsabilidades jurídicoadministrativas; pero les abrió también una oportunidad para guiar sus esfuerzos de modernización, enfatizar el enfoque por resultados que les interesaba y diferenciarse de lo hecho durante el periodo presidencial anterior.

En tercer lugar, en cuanto a las razones para impulsar el proceso de transferencia del PMG, podría decirse que los funcionarios mexicanos se involucraron en él respondiendo fundamentalmente a necesidades administrativas e intereses propios. Dicho de otra forma, si bien diversos actores internacionales (BID, Banco Mundial, CEPAL) aparecen a lo largo de la historia, no pareciera haber existido ningún elemento de coerción en el desarrollo de la reforma. Asimismo, aunque el proceso desembocó en un programa mexicano de denominación parecida y con algunos elementos similares a su punto de referencia chileno, tampoco pareciera haber existido entre los funcionarios mexicanos (ni siquiera entre los de la SHCP) el deseo de imitar el PMG por razones simbólicas/de legitimación internacional. Por otra parte, resulta menos sencillo determinar hasta qué punto el proceso fue resultado de las actividades de investigación/aprendizaje de un grupo de funcionarios, y no el producto de intercambios más complejos y extensivos en el marco de una red o comunidad epistémica internacional.

En cuarto lugar, la discusión de la sección previa ha dejado en claro que, a pesar de las intenciones originales (o por lo menos de lo que parecieran haber sido éstas), se transfirieron algunos componentes del PMG original y una etiqueta (policy label) más o menos parecida (PEMG). Así, como ha ocurrido en buena parte de las experiencias de transferencia estudiadas por la literatura, el proceso no dio como resultado el traslado de un programa íntegro, sino más bien la construcción de un híbrido que combinó elementos del modelo original y del sistema administrativo mexicano en el que se insertó. Asimismo, pareciera que los funcionarios mexicanos, por lo menos en la segunda fase de la transferencia, también extrajeron algunas lecciones más generales acerca del funcionamiento del PMG (e.g. el uso de un esquema común, pero complementado por esquemas para cada agencia). Aunque se consultó a expertos académicos y quizás se revisaron algunos documentos de evaluación sobre el funcionamiento del PMG, es complicado saber si los funcionarios mexicanos también obtuvieron algunas lecciones negativas (es decir sobre qué no hacer). 
Finalmente, en cuanto a las restricciones u obstáculos que la transferencia de un programa o política puede enfrentarse, el estudio de caso presentado pareciera arrojar hallazgos ambivalentes. Por una parte, por la naturaleza del tema (algo sumamente técnico y poco discutido fuera de los ministerios), no pareciera haber existido oposición alguna de los partidos políticos o la opinión pública. Tampoco pareciera que en la transferencia del PMG se tuvieron limitaciones de recursos, pues además de la donación (y luego crédito) del BID (y más adelante del Banco Mundial también), tanto la SHCP como la SFP contaron con los recursos humanos y presupuestales necesarios para desarrollar sus viajes, estudiar el caso chileno e implementar el esquema del PEMG. Responder si hubo o no problemas cognitivos o de aprendizaje es complicado pues no se puede saber hasta qué punto los participantes comprendieron o no el tema y sus implicaciones (consecuencias administrativas, institucionales, políticas). Sin embargo, por el nivel técnico y experiencia profesional de los mismos, así como por el amplio acceso que tuvieron a información detallada sobre el SECGPMG, resulta difícil imaginar que hayan existido grandes problemas de este tipo. Por otra parte, sí parecieran haber existido complicaciones asociadas al entorno institucional receptor. Pero como se discutirá en el siguiente apartado, no se trató de situaciones derivadas de un choque entre las características del programa adoptado y las condiciones del sistema al cual se integró. El asunto más bien tuvo que ver con las diferentes posturas de distintos actores institucionales en cuanto a sus prioridades y expectativas respecto de la transferencia del PMG.

\section{LA TRANSFERENCIA DE POLÍticas A LA LUZ DEL PMG-PEMG}

El apartado anterior ha mostrado que el proceso de transferencia del PMGPEMG en buena medida refleja muchos aspectos ya resaltados en la literatura existente. Este hecho nos ayuda a comprender mejor la experiencia, en la medida en que las particularidades del caso adquieren mayor sentido al contrastarlas (o, mejor dicho, contextualizarlas) en el cúmulo de hallazgos empíricos de los estudios en la materia. Así, el enfoque de transferencia de políticas no sólo resulta útil al proveer un conjunto de preguntas básicas de investigación a partir de las cuales estructurar la descripción del caso, sino que provee un trasfondo para entender e interpretar mejor la experiencia particular de cuando el PMG "viajó" a México.

Sin embargo, el estudio de caso también pone sobre la mesa una serie de cuestiones importantes que la literatura no ha discutido aún con el detenimiento profundidad necesarios. En primer término, las razones por las cuales una política termina siendo algo ligera/completamente distinto una vez transferida a otro entorno. En el caso del PMG, por ejemplo, las explicaciones existentes no son del todo satisfactorias. Por un parte, 
es posible notar a lo largo del proceso diversos esfuerzos por adaptar el programa a un nuevo sistema administrativo, tal y como sugiere Rose (1993, 2005) en sus estudios pioneros. Asimismo, en línea con lo que otros autores han propuesto (Pedersen 2007, Sahlin y Wedlin 2008), los funcionarios mexicanos y los consultores chilenos indudablemente intentaron editar el programa, sus contenidos y su lenguaje, para traducirlo al contexto mexicano. Pero en última instancia, el programa acabó siendo algo distinto no por estas manipulaciones/ajustes deliberados, sino por causa de los conflictos inter-burocráticos y las negociaciones entre la SHCP y la SFP. Puesto en otros términos, la historia del PMG-PEMG es, antes que cualquier otra cosa, la de una transferencia de políticas disputada, en la que los intereses, prioridades y expectativas contrastantes de los actores clave involucrados (junto con los conflictos derivados de los mismos) acabaron condicionando el desarrollo y resultados del proceso (Dussauge por aparecer c).

En segundo término, y en relación directa con el punto anterior, el estudio de caso pone en evidencia que el supuesto de que las transferencias ocurren como procesos en los que una política/institución "viaja" del país A al país B resulta demasiado simplista. Aunque no se ha discutido aquí la posibilidad de que un país aprenda y combine las ideas provenientes de varias naciones (véanse Pollitt 2003, Dussauge por aparecer a), el caso estudiado sí muestra que dentro de cada uno de los países involucrados hay más de un actor que puede intervenir de manera determinante en el proceso. Si bien el artículo ha presentado la experiencia de un programa que "viajó" de Chile a México, también se ha detallado cómo dentro de las fronteras de éste último país hubo más de un actor con capacidad de influir la transferencia del PMG.

En tercer término, la discusión del caso también pone sobre la mesa la necesidad de repensar cuál es el papel de los organismos internacionales en los procesos de transferencia de políticas, por lo menos en el área de las reformas administrativas (Walt et al. 2004, Dussauge por aparecer d). La literatura especializada ha tendido a sugerir que dichas organizaciones influyen en la adopción de políticas/instituciones generalmente a través de presiones directas o condiciones vinculadas a préstamos monetarios (Peters 1997, Dolowitz y Marsh 2006). Pero al menos en la experiencia del PMG-PEMG, los organismos internacionales parecieran haber usado otros medios para influir el proceso, como el otorgamiento de donativos o la contratación subvencionada de expertos seleccionados por ellos mismos. Más aún, uno podría cuestionar hasta dónde dichas acciones realmente influyeron en el proceso de transferencia del PMG, en los contenidos del programa en su versión mexicana o en los resultados del proceso de 
implementación.

Por último, la narración del proceso de transferencia del PMG-PEMG sirve para reiterar la importancia de los aspectos temporales en esta materia. Aunque el estudio de caso no ha abundado sobre este punto, a lo largo de la discusión han quedado en evidencia, por ejemplo, que la transferencia no fue inmediata, sino que tomó cierto tiempo (3-5 años), y eso antes de que la implementación diera inicio; que el proceso tuvo cuando menos dos etapas en distintos tiempos; y que el modelo chileno sirvió como tal porque los funcionarios de la SHCP lo estudiaron en el momento adecuado, es decir durante la última parte del sexenio 2000-2006 y con miras al sexenio 2006-20 I 2 (Dussauge 20I2c).

Por supuesto, los temas anteriores son meramente indicativos y eso en por lo menos dos sentidos. Primero, porque no elaboran sobre las preguntas de investigación específicas que podrían seguirse, sino que apenas esbozan un conjunto de áreas que, a juicio de este autor, valdría la pena analizar con mayor profundidad: los impactos de las disputas burocráticas en los patrones/contenidos de los programas transferidos; la existencia e importancia relativa de múltiples actores/modelos en los procesos de aprendizaje transnacional; las varias formas en que los organismos internacionales pueden influir en aquéllos; y la necesidad de tomar en cuenta los aspectos temporales al estudiar estos temas. Segundo, porque incluso partiendo del supuesto de que las cuatro áreas mencionadas son realmente merecedoras de recibir mayor atención, de ninguna manera agotan las cuestiones que en materia de transferencia de políticas quedan todavía por investigar.

En cualquier caso, y como se dijo al principio del artículo, no se ha tratado aquí de ofrecer respuestas concluyentes o sumarios definitivos. Por el contrario, estas páginas han tratado simplemente de mostrar tres cosas: primero, que el enfoque de transferencia de políticas puede ayudarnos a estudiar ciertos aspectos de los procesos latinoamericanos de modernización administrativa que a la fecha han sido poco discutidos (e.g. de dónde vienen las ideas de reforma, cómo "viajan" y por qué se transforman al llegar a un nuevo entorno político-administrativo); segundo, que la experiencia del traslado del PMG chileno a México dio como resultado un programa fundamentalmente distinto, a pesar de las similitudes en sus denominaciones; $y$, tercero, que la discusión detallada de este caso empírico resulta útil, además, para enriquecer las discusiones teóricas de la literatura especializada. Si los lectores quedan convencidos de que estos tres puntos se han cubierto de manera satisfactoria, entonces el artículo habrá alcanzado sus objetivos. Pero si entre los lectores quedan dudas, inquietudes e incluso la necesidad de debatir/rebatir las afirmaciones aquí 
propuestas, y eso a su vez trae consigo nuevas discusiones/publicaciones sobre cualquiera de los temas que han cruzado estas páginas, entonces el artículo sí que habrá satisfecho su motivación original: contribuir a generar un mayor interés acerca de cómo y por qué nuestros gobiernos nacionales se interesan en aprender de las experiencias de otros países para (re)diseñar sus instituciones y políticas públicas. 


\section{REFERENCIAS}

Arenas de Mesa, A. y Berner H. (2010). Presupuesto por Resultados y la Consolidación del Sistema de Evaluación y Control de Gestión del Gobierno Central. Santiago: DIPRES.

Armijo, M. (2003). La Evaluación de la Gestión Pública en Chile. En Cunill N. y Ospina S. (Eds.), Evaluación de Resultados para una Gestión Pública Moderna y Democrática: Experiencias Latinoamericanas. Caracas: CLAD-AECI/ MAP/ FIIAPP.

Barzelay, M. (2003). Introduction: The Process Dynamics of Public Management Policymaking. International Public Management Journal, $6(3), 25 \mathrm{I}-28 \mathrm{I}$.

Bennett, C. (I99 I). How States Utilize Foreign Evidence. Journal of Public Policy, I I (I), 3I-54.

. (1997). Understanding Ripple Effects: The Cross-National Adoption of Policy Instruments for Bureaucratic Accountability. Governance, Io (3), $213-233$.

Benson, D. y Jordan A. (20II). What Have We Learned from Policy Transfer Research? Dolowitz and Marsh Revisited. Political Studies Review, 9 (3), 366-378.

Bissessar, A. M. (Ed.). (2002). Policy Transfer, New Public Management and Globalization. Lanham: University Press of America.

Bulmer, S., Dolowitz D., Humphreys P. y Padgett S. (2007). Policy Transfer in European Union Governance. London: Routledge.

Common, R. (200 I). Public Management and Policy Transfer in South East Asia. Aldershot: Ashgate.

Collier, D. y Mesick R. E. (1975). Prerequisites versus Diffusion: Testing Alternative Explanations of Social Security Adoption. American Political Science Review, 69 (4), I 299-I 3 I 5.

Culebro, J. (2008). Transferencia de Políticas y Construcción de Lecciones para la Modernización Administrativa. Revista Venezolana de Gerencia, I 2 (44), 53 I - 542.

Diario Oficial de la Federación. (2006). Decreto que Establece las Medidas de Austeridad y Disciplina del Gasto de la Administración Pública. 
Presidencia, 4 de diciembre.

- (2008). Decreto por el que se Aprueba el Programa Especial de Mejora de la Gestión en la Administración Pública Federal 2008-20 I 2. Secretaría de la Función Pública, io de septiembre.

Dolowitz, D. P. \& Marsh D. (I996). Who Learns What from Whom: a Review of the Policy Transfer Literature. Political Studies, XLIV (4), 343-357.

. (2000). Learning from Abroad: The Role of Policy Transfer in Contemporary Policy-Making. Governance, I 3 (I), 5-23.

Dussauge, M. (2008). Paradoxes of Public Sector Reform: The Mexican Experience, 2000-2007. International Public Management Review, 9 (I), 56-75.

- (2012a). On the State and Future of Policy Transfer Research: Benson and Jordan Revisited. Political Studies Review, ro (3), 3 I 3-324.

. (2012b). Chile's Monitoring and Evaluation System, I994-20Io. En López-Acevedo G., Krause Ph. y Mackay K. (Eds.), Building Better Policies. Washington, DC: World Bank.

(20 I 2c). The Neglected Dimension: Bringing Back Time into Cross-National Policy Transfer Studies. Ponencia presentada en el ECPR Joint Sessions of Workshops, abril, Amberes.

. (en prensa a). Cross-National Policy-Learning and "Management by Results": Chile and Mexico in Comparative Perspective, I99o-20Io. London School of Economics and Political Science.

- (en prensa b). Dos Décadas de Estudios sobre Aprendizaje Transnacional: lecciones y propuestas.

. (en prensa c). Contested Policy Transfer. When Chile's Program for Management Improvement Travelled to Mexico...”. En Carroll P. \& Common R. (Eds.). Policy Transfer and Learning in Public Policy and Management. London: Routledge.

- (en prensa d). La Transferencia de Políticas como Fuente de Innovación Gubernamental: Promesas y Riesgos. Estado, Gobierno y Gestión Pública. Revista Chilena de Administración Pública.

. (en prensa e). Leaders, Followers, or Partners? Understanding the "Influence" of International Organizations in the Cross-National 
Transfer of Administrative Reforms.

Evans, M. (Ed.). (2004). Policy Transfer in a Global Perspective. Aldershot: Ashgate. . (2009). Policy Transfer in Critical Perspective. Policy Studies, 30 (3), 243-268.

Evans, M. y Davies J. (I999). Understanding Policy Transfer: A Multilevel, Multi-Disciplinary Perspective. Public Administration, 77 (2), 36I-385.

Fawcett, P. y Marsh D. (201 2). Policy Transfer and Policy Success: The Case of the Gateway Review Process (200I-2010). Government and Opposition, 47 (2), I 62-I 85 .

González, J. (2008). La Mejora de la Gestión y el Enfoque hacia Resultados en el Ámbito Internacional: ¿Qué hacer? ¿Hacia dónde ir? ¿Cómo Actuar? Revista de Administración Pública, I I 7 XLIII (3), 49-62.

Gray, V. (1973). Innovation in the States: A Diffusion Study. American Political Science Review, 67 (4), I I74-I I 85.

Guzmán, M. (2005). Sistema de Control de Gestión y Presupuesto por Resultados: La Experiencia Chilena. Santiago de Chile: DIPRES.

. (20Ir). Programas de Mejoramiento de Gestión. El caso de Chile. Mimeo.

Heilmann, S. \& Schulte-Kulkmann N. (20I I). The Limits of Policy Diffusion: Introducing International Norms of Anti-Money Laundering into China's Legal System. Governance, 24 (4), 639-664.

James, O. y Lodge M. (2003). The Limitations of 'Policy Transfer' and 'Lesson Drawing' for Public Policy Research". Political Studies Review, I (2), I79-I 83 .

Jordana, J. y Levi-Faur D. (2005). The Diffusion of Regulatory Capitalism in Latin America: Sectoral and National Channels in the Making of a New Order. The ANNALS of the American Academy of Political and Social Science, 598 (I), IO2-I24.

Lodge, M. (2003). Institutional Choice and Policy Transfer: Reforming British and German Railway Regulation. Governance, I 6 (2), I 59-I78.

Ludwikoski, R. R. (2003). Latin American Hybrids Constitutionalism: 
The United States Presidentialism in the Civil Law Melting Pot. Boston University International Law Journal, 2 I (I), 29-6I.

Majone, G. (I99I). Cross-National Sources of Regulatory Policymaking in Europe and the United States. Journal of Public Policy, I I (I), 79I06.

Marcel, M. (2000). Indicadores de Desempeño como Instrumento de Modernización en el Estado de Chile. Perspectivas, 2 (I), 49-82.

. (2006). Reflexiones acerca del Proceso de Modernización del Estado en Chile y Desafíos Futuros. Reforma y Democracia. Revista del CLAD, $34,217-232$.

Marsh D. \& Sharman J. C. (2009). Policy Diffusion and Policy Transffer. Policy Studies, 30 (3), 269-288.

Massey, A. (2009). Policy Mimesis in the Context of Global Governance. Policy Studies, 30 (3), 383-395.

May, E., Shand D., Mackay K., Rojas F. y Saavedra J. (Eds.). (2006). Towards the Institutionalization of Monitoring and Evaluation Systems in Latin America and the Caribbean. Washington, DC: World BankInter-American Development Bank.

Meseguer, C. (2009). Learning, Policy Making, and Market Reforms. Cambridge: Cambridge University Press.

Mossberger, K. (2000). The Politics of Ideas and the Spread of Enterprise Zones. Washington, DC: Georgetown University Press.

Mossberger, K. y Wolman H. (2003). Policy Transfer as a Form of Prospective Policy Evaluation: Challenges and Recommendations. Public Administration Review, 63 (4), 428-440.

Nickson A. (2002). Transferencia de Políticas y Reforma en la Gestión del Sector Público en América Latina: El caso del New Public Management. Reforma y Democracia. Revista del CLAD, 24, I I3-I42.

Orellana, P. (2004). Contra la Burocracia. Disponible en www. probidadenchile.cl.

Page, E. (2000). Future Governance and the Literature on Policy Transfer and Lesson Drawing. Ponencia presentada en el ESRC Future Governance Workshop, enero, Londres.

. (2003). Europeanization and the Persistence of National Systems. 
En Hayward J. y Menon A. (Eds.), Governing Europe. Oxford: Oxford University Press.

Page, E. y Mark-Lawson J. (20 Io). Outward-Looking Policy Making. En Bochel H. y Duncan S. (Eds.), Making Policy in Theory and Practice. Bristol: Policy Press.

Pardo, M. (2009). La Modernización Administrativa en México. México: El Colegio de México.

Pedersen, L. H. (2007). Ideas are Transformed as they Transfer: A Comparative Study of Eco-Taxation in Scandinavia. Journal of European Public Policy, I4 (I), 69-77.

Peters, B. G. (1 997). Policy Transfers Between Governments: The Case of Administrative Reforms. West European Politics, 20 (4), 7 I-88.

Pollitt, C. (2003). Public Management Reform: Reliable Knowledge and International Experience. OECD Journal on Budgeting, 3 (3), I 2 I-I 36.

Ramírez, A. (2004). El Proceso de Reforma del Estado y Modernización de la Gestión Pública en Chile. Madrid: INAP.

Randma-Liiv, T. y Kruusenberg R. (2012). Policy Transfer in Immature Policy Environments: Motives, Scope, Role Models and Agents. Public Administration and Development, 32 (2), I 54-166.

Robertson, D. (I99I). Political Conflict and Lesson-Drawing. Journal of Public Policy, I I (I), 55-78.

Robertson, D. y Waltman J. L. (I993). The Politics of Policy Borrowing. En Finegold D., McFarland L. y Richardson W. (Eds.), Something Borrowed, Something Learned? Washington, DC: The Brookings Institution Press.

Rogers, E. M. (2003). Diffusion of Innovations. New York: Free Press.

Rose, R. (I99I). What is Lesson-Drawing? Journal of Public Policy, I I (I), 3-30.

. (1993). Lesson-Drawing in Public Policy. Chatham, NJ: Chatham House Publishers. . (2005). Learning from Comparative Public Policy. A Practical guide. London: Routledge. 
Sahlin, K. y Wedlin L. (2008). Circulating Ideas: Imitation, Translation, and Editing. En Greenwood, R., Oliver, C., Sahlin, K. y Suddaby, R. (Eds.), The SAGE Handbook of Organizational Institutionalism. London: Sage.

Secretaría de la Función Pública. (2008). Programa Especial de Mejora de la Gestión. México: SFP.

- (2010). Manual de Operación del Módulo Institucional del Programa de Mejora de la Gestión 20Io. México: SFP.

Sharman, J. C. (20 Io). Dysfunctional Policy Transfer in National Blacklists. Governance, 23 (4), 623-639.

Simmons, B. A., Dobbin F. y Garrett G. (2008). The Global Diffusion of Markets and Democracy. Cambridge: Cambridge University Press.

Stone, D. (1999). Learning Lessons and Transferring Policy Across Time, Space and Disciplines. Politics, I9 (I), 5 I-59.

- (2000). Non-Governmental Policy Transfer: The Strategies of Independent Policy Institutes. Governance, I 3 (I), 45-62.

(2004). Transfer Agents and Global Networks in the "Transnationalization" of Policy. Journal of European Public Policy, I I (3), 545-566.

Walker, J. L. (1969). The Diffusion of Innovations among the American States. American Political Science Review, 63 (3), 880-899.

Walt, G., Lush L. y Ogden J. (2004). International Organizations in Transfer of Infectious Diseases: Iterative Loops of Adoption, Adaptation, and Marketing. Governance, I7 (2), I89-2 Io.

Waltman, J. L. (I980). Copying Other Nation's Policies. Cambridge, MA: Schenkman Publishing Company.

Westney, E. D. (1987). Imitation and Innovation. The Transfer of Western Organizational Patterns in Meiji Japan. Cambridge, MA: Harvard University Press.

Weyland, K. (Ed.). (2004). Learning from Foreign Models in Latin American Policy Reform. Washington, DC: Woodrow Wilson Center Press.

. (2006). Bounded Rationality and Policy Diffusion. Princeton: Princeton University Press. 
Wolman, H. (1992). Understanding Cross National Policy Transfers: The Case of Britain and the US. Governance, 5 (I), 27-45. (2009). Policy Transfer: What We Know About What Transfers, How It Happens, and How to Do It. The George Washington University Institute of Public Policy Papers. Working Paper 038.

Wolman, H. y Page E. (2002). Policy Transfer among Local Governments: An Information-Theory Approach. Governance, I 5 (4), 477-50I.

Zaltsman, A. (2009). The Effects of Performance Information on Public Resource Allocations: A Study of Chile's Performance Based Budgeting System. International Public Management Journal, I 2 (4), 450-483.

Recibido: 08-06-20 I 2

Aceptación de la versión final: o I-08-20 I 2 